\title{
NORBERTO BOBBIO: teoria política e direitos humanos
}

\author{
Norberto Bobbio: theory politics and \\ human rights
}

Samuel Antonio Merbach de Oliveira
Doutorando em Filosofia pela PUC - São Paulo.
Doutorando em Direito Internacional pela Universidade Autônoma de Assunção.
São Paulo - SP. e-mail: samuelmerbach@ @ol.com.br

\section{Resumo}

Este artigo tem por objetivo analisar a proposta de Bobbio de unir os aspectos positivos do liberalismo e do socialismo, no projeto denominado socialismo-liberal, que conjuga as duas correntes do pensamento político ocidental com a democracia, estabelecendo, na mesma estrutura, três características da cidadania: as liberdades civis, as garantias políticas e os direitos humanos.

Palavras-chave: Democracia; Cidadania; Regras do Jogo; Tolerância; Direitos Humanos.

\begin{abstract}
The purpose of this article is to analyze Bobbio's proposal to unite the positive aspects of liberalism and socialism in the project designated liberal socialism, which combines the two schools of western political thought with democracy, thus establishing three characteristics of citizenship within the same structure: civil liberties, political guarantees and human rights.
\end{abstract}

Keywords:Democracy; Citizenship; Game Rules; Tolerance; Human Rights. 


\section{Introdução}

Em 9 de janeiro de 2004 faleceu um dos maiores filósofos políticos contemporâneos, o italiano Norberto Bobbio. Bobbio foi senador vitalício da Itália, nasceu em Turim, onde estudou direito e filosofia, foi professor universitário e jornalista. É conhecido como filósofo que se aplicou ao estudo dos direitos humanos, da filosofia e da política.

Assim, o propósito deste artigo é examinar a teoria de Bobbio em relação às questões centrais da democracia, da liberdade, da igualdade, da república e dos direitos humanos, que foram os elementos básicos de sua atividade intelectual e política.

Dessa maneira, Bobbio contribuiu para aproximar as pessoas pelo debate, colaborando, assim, para o exercício da cidadania e o avanço dos direitos humanos nas democracias ocidentais. contemporâneos.

Por isso, Norberto Bobbio é considerado um dos maiores filósofos

\section{Direitos humanos}

De fato, o estudo dos direitos humanos conduz, necessariamente, à análise de sua relação com o próprio homem, seu destinatário. Dessa maneira, no plano histórico, busca-se a justificação dos valores naquilo que representam ao homem, que lhe possibilitem o desenvolvimento da personalidade, da convivência pacífica e da solidariedade social. No tocante à definição de direitos humanos, constata-se que isso vem sendo feito de modo vago e insatisfatório, ainda mais quando se busca um fundamento absoluto, único. Nesse sentido, cabe considerar as seguintes definições de Bobbio:

1. tautológicas - estabelecem que direitos do homem são os que cabem ao homem enquanto homem. Não indicam qualquer elemento que os caracterize;

2. formais - desprovidas de conteúdo e meramente portadoras do estatuto proposto para esses direitos. Assim, direitos do homem são aqueles que pertencem, ou deveriam pertencer, a todos os homens, ou dos quais nenhum homem pode ser despojado;

3. teleológicas - embora tragam alguma menção ao conteúdo, pecam pela introdução de termos avaliativos, ao sabor da 
ideologia do intérprete, como "direitos do homem são aqueles cujo reconhecimento é condição necessária para o aperfeiçoamento da pessoa humana, ou para o desenvolvimento da civilização etc." (BOBBIO, 1992, p. 17).

Assim, como sabemos, devemos analisar que a dignidade do ser humano enquanto membro vivente de uma sociedade está situada num contexto político atualmente marcado por grandes injustiças sociais, profundas diferenças socioeconômicas e pelas não menos trágicas disparidades de distribuição de renda. Para que um ser humano tenha direitos e possa exercê-los, é indispensável que seja reconhecido e tratado como pessoa, o que vale para todos os seres humanos. Reconhecer e tratar alguém como pessoa é respeitar sua vida, mas exige que também seja respeitada a dignidade, própria de todos os seres humanos. Nenhum homem deve ser humilhado ou agredido por outro, ninguém deve ser obrigado a viver em situação de que se envergonhe perante os demais, ou que os outros considerem indigna ou imoral.

No entanto, na realidade, enfrentamos sérios problemas acerca dos direitos sociais, evidenciando que um dos princípios fundamentais, a Dignidade da Pessoa Humana, não foi efetivamente concretizado. Com efeito, não é possível enxergar a categoria de cidadão naquele que não dispõe da própria dignidade, de uma vida digna. Assim, existe uma grande distância, um paradoxo entre o que está escrito nas Declarações e o que há de concreto, pois não basta apenas estar inserido nos textos internacionais e na maioria das constituições dos países ocidentais, sendo fundamental a ação do Estado, para realizá-los.

Nesse contexto, temos as diversas declarações de direitos do homem, como a Declaração Americana (1776), a Declaração Francesa (1789) e a Declaração da ONU (1948), que influenciaram o surgimento das proteções jurídicas dos direitos fundamentais em diversos países. De fato, é o fenômeno da positivação das declarações de direitos que expõe o caráter inovador e revolucionário da condição humana. Essas declarações despontavam como alternativa para garantir a estabilidade na tutela dos direitos tidos como essenciais à condição humana. Esse processo evolutivo ainda ocorre, pois à medida que a humanidade avança, outros direitos devem ser garantidos e outras tantas violações desses direitos precisam ser coibidas.

O reconhecimento e a proteção dos direitos fundamentais do homem no mundo alcançaram seu estágio atual de forma lenta e gradual, passando por várias fases. Nesse contexto, ressalta Bobbio (1992, p. 5): 
Do ponto de vista teórico, sempre defendi - e continuo a defender, fortalecido por novos argumentos - que os direitos do homem, por mais fundamentais que sejam, são direitos históricos, ou seja, nascidos em certas circunstâncias, caracterizadas por lutas em defesa de novas liberdades contra velhos poderes, e nascidos de modo gradual, não todos de uma vez e nem de uma vez por todas.

Estas etapas da evolução desses direitos são chamadas de gerações, pois foram construídas em diferentes momentos históricos.

Para Bobbio, a Declaração Universal dos Direitos do Homem representa uma síntese do passado e uma inspiração para o futuro. $\mathrm{O}$ reconhecimento e a proteção dos direitos do homem devem estar presentes nas principais constituições democráticas modernas. Por conseguinte, na concepção bobbiana, os direitos humanos se afirmaram historicamente em quatro gerações: $1^{a}$ Geração: Direitos Individuais - pressupõem a igualdade formal perante a lei e consideram o sujeito abstratamente; $2^{a}$ Geração: Direitos Coletivos - os direitos sociais, nos quais o sujeito de direito é visto no contexto social, ou seja, analisado em uma situação concreta; $3^{\text {a }}$ Geração: Direitos dos Povos ou os Direitos de Solidariedade: os direitos transindividuais, também chamados direitos coletivos e difusos, e que basicamente compreendem os direitos do consumidor e os relacionados à questão ecológica; $4^{\mathrm{a}}$ Geração: Direitos de Manipulação Genética - relacionados à biotecnologia e bioengenharia, tratam de questões sobre a vida e a morte e requerem uma discussão ética prévia (BOBBIO, 1992).

Como sabemos, o respeito aos direitos humanos somente é possível nos países democráticos. Assim, os direitos humanos e a democracia são elementos fundamentais para o sucesso do regime socialista-liberal defendido por Bobbio.

\section{Liberalismo}

O termo liberalismo tornou-se conhecido após a Revolução Francesa, em 1789. O liberalismo é uma doutrina do Estado limitado tanto com respeito aos seus poderes quanto às suas funções. $\mathrm{O}$ primeiro é o Estado de direito e o segundo é o Estado mínimo.

Contudo, é possível que um Estado de direito não seja mínimo, como também um Estado mínimo que não seja um Estado de direito. O Estado de direito se opõe ao Estado absoluto; o Estado mínimo se contrapõe ao Estado máximo. 
Por Estado de direito entende-se geralmente um Estado em que os poderes públicos são regulados por normas gerais e devem ser exercidos no âmbito das leis que os regulam. Trata-se da doutrina da superioridade do governo das leis sobre o governo dos homens.

O Estado de direito significa não só subordinação dos poderes públicos às leis, mas também subordinação das leis ao limite material do reconhecimento de alguns direitos fundamentais considerados constitucionalmente e, portanto, invioláveis.

Integram o Estado de direito os mecanismos constitucionais que impedem o exercício arbitrário e ilegítimo do poder, bem como o abuso do poder. Os mais importantes desses mecanismos são:

1) o controle do Poder Executivo pelo Legislativo; 2) o eventual controle do parlamento no exercício do Poder Legislativo ordinário por parte de uma corte jurisdicional, a quem se pede a averiguação da constitucionalidade das leis; 3 ) uma relativa autonomia do governo local em todas as suas formas e graus, com respeito ao governo central; 4, uma magistratura independente do poder político. (BOBBIO, 1994, p. 19).

Os mecanismos constitucionais que caracterizam o Estado de direito têm o objetivo de defender o indivíduo dos abusos do poder.

Para os liberais, a liberdade individual é garantida, mais do que pelos mecanismos constitucionais, também pelo fato de que ao Estado são reconhecidas tarefas limitadas à manutenção da ordem pública interna e internacional. Pode-se dizer que a limitação das tarefas do Estado constitui condição sine qua non do controle dos poderes coercitivos do Estado. O Estado mínimo é mais controlável do que o Estado máximo.

Uma vez defendida a liberdade no sentido predominante da doutrina liberal como liberdade em relação ao Estado, a formação do Estado liberal pode ser identificada como o progressivo alargamento da esfera de liberdade individual diante dos poderes públicos.

Mas mesmo o objetivo liberal de construir um "Estado limitado" pode ser compreendido de duas formas distintas: o sentido liberal de limitação dos seus poderes (Estado de direito) ou o sentido liberista de limitação das suas funções (Estado mínimo). Trata-se da identificação do liberalismo com a defesa das forças de mercado. Em sentido contrário, temos o termo "liberista" serve para designar os adeptos do liberalismo econômico ao passo que liberalismo refere-se ao universo do liberalismo político (BOBBIO, 1994, p. 39-87). 


\section{Liberalismo e democracia}

O início das democracias liberais se evidenciou nas revoluções burguesas que entre os séculos XVIII e XIX ocorreram nos Estadas Unidos e na Europa. Fatos importantes como A Guerra de Independência estado-unidense (1776), a Revolução Francesa (1789) e as diversas revoluções européias de 1848 que destruíram o absolutismo, legado do feudalismo.

$\mathrm{Na}$ vanguarda desses acontecimentos estava a nova classe social emergente, a burguesia, que derrotou as monarquias de direito divino, consolidando a liberdade econômica, reduzindo o poder da Igreja (separação entre Igreja e Estado) e instituindo as noções de cidadão e de representação política: noções de homem, de voto.

O termo liberalismo ganhou destaque após a Revolução Francesa, em 1789. Em sua origem, o liberalismo não se confunde com a democracia. De fato, nem todos os Estados originariamente liberais tornaram-se democráticos. Entretanto, os Estados democráticos existentes foram originariamente liberais. Assim, liberalismo e democracia não são interdependentes: um Estado liberal não é necessariamente democrático e um governo democrático se transforma necessariamente num Estado liberal. Isso porque, enquanto o ideal do primeiro é limitar o poder, o do segundo é distribuir o poder.

Liberalismo e democracia tratam de assuntos divergentes: o liberalismo à questão das funções do governo e à limitação de seus poderes; a democracia ao problema de quem deve governar e com quais procedimentos. O liberalismo exige que todo poder seja submetido a limites, inclusive o da maioria. A democracia, ao contrário, chega a considerar a opinião da maioria o único limite aos poderes do governo. É uma teoria dos limites do poder do Estado. Tais limites valem para quem quer que detenha o poder político, inclusive para um regime democrático em que todos os cidadãos têm o direito de participar, mesmo que indiretamente, da tomada das grandes decisões, e cuja regra é a regra da maioria.

Na formulação hoje mais corrente, o liberalismo é a doutrina do "Estado mínimo". Ao contrário dos anarquistas, para quem o Estado é um mal absoluto e deve, pois, ser eliminado, para o liberal o Estado é sempre um mal, mas é necessário, devendo, portanto, existir, mas dentro dos limites mais restritos.

Nesse contexto, Bobbio defende o liberalismo democrático, contra a visão instrumental de democracia dos liberistas. Com o avanço do socialismo no mundo, o liberalismo acabou se concentrando na luta pela economia de 
mercado e pela liberdade econômica. Com isso, de doutrina do Estado de Direito, o liberalismo se transformou em doutrina do Estado mínimo.

Nesse contexto, Bobbio entende: “a) que hoje o método democrático seja necessário para a salvaguarda dos direitos fundamentais da pessoa, que estão na base do Estado liberal; b) que a salvaguarda desses direitos seja necessária para o correto funcionamento do método democrático" (BOBBIO, 1994, p. 43).

\section{Socialismo: a doutrina marxista}

De fato, para o marxismo, apenas num sistema econômico comunista é possível se ter uma sociedade democrática. Entende a democracia como o governo do povo, uma vez que se fundamenta na realização do interesse do povo e, portanto, na sua verdadeira vontade. A doutrina marxista entende que a democracia como a melhor forma de governo, mas isso só é possível sob o socialismo, visto como o melhor sistema econômico, que se desenvolve a partir de uma interpretação econômica da sociedade, segundo a qual os fenômenos políticos, como o Estado e o Direito, são apenas uma superestrutura posta acima da realidade econômica, formada pelas relações de produção. É a primazia do econômico sobre o político.

De fato, na sociedade capitalista, a minoria burguesa detém a posse dos meios de produção, sendo, por isso, o grupo economicamente dominante, $\mathrm{o}$ que contradiz veementemente a democracia enquanto governo para a maioria.

Dessa maneira, apenas quando a maioria se tornar o grupo economicamente dominante, o que conforme a tese marxista só será possível por meio da socialização dos meios de produção, é que teremos realmente a democracia.

\section{Bobbio e os comunistas italianos}

De fato, Bobbio, além de teórico político, também teve importante participação política na Itália. Sua militância teve como premissas fundamentais: a defesa da liberdade, do socialismo, da tolerância e da democracia

Em dezembro de 1943, militava no clandestino Partido da Ação (que recolhia a herança de Piero Gobetti e Carlo Rosselli) contra o fascismo e pela libertação da Itália, entendia que esta não era uma luta de classes e sim uma revolução democrática, tendo nessa época um diálogo permanente com os 
comunistas do PCI (hoje Partido Democrático da Esquerda), em que os via "não adversários, mas interlocutores" e reconhece o valor de suas idéias.

Dessa maneira, como representante do socialismo-liberal, o Partido da Ação era totalmente contrário ao fascismo que fora antiliberal na política e anti-socialista na economia.

Na luta contra o fascismo, Bobbio dialogou com seus adversários comunistas italianos acerca dos temas da liberdade, da democracia, para resistir contra a ofensiva da direita reacionária (REGO, 2001).

Para Bobbio, os comunistas não são inimigos que devem ser combatidos, mas sim devemos considerá-los como interlocutores em um diálogo acerca das razões da esquerda.

Com efeito, na obra Política e Cultura, Bobbio dialoga de maneira serena e civilizada com os comunistas italianos acerca da defesa dos direitos humanos, em particular os direitos da liberdade. A discussão começou com Ranuccio Bianchi Bandelli, seguiu com Galvano della Volpe e finalizou com a intervenção de Palmiro Togliati. Esse diálogo é um exemplo de tolerância, levando em consideração a importância da função moderadora e mediadora de dogmatismos opostos (BOBBIO, 1955).

Bobbio debateu com os discípulos de Gramsci temas como: o projeto de democracia indicado pelos comunistas como alternativa à democracia representativa dos liberais; e a compatibilidade, ou não, da proposta de transformação socialista com a continuidade da democracia, entendida como um conjunto de regras que regulam o jogo político.

Bobbio não foi marxista e nem antimarxista. Considerava a obra de Marx como um clássico que devia ser lido e relido para se averiguar o que permanece da sua obra.

Norberto Bobbio, levantando sempre o problema central da relação entre socialismo e democracia, critica o suposto desprezo dos comunistas italianos pela democracia liberal em prol da idéia de ditadura do proletariado.

Embora tenha algumas idéias contrárias ao marxismo, entende que não seria possível, sem o marxismo, entender a história sob a ótica dos oprimidos, ganhando assim uma nova perspectiva do mundo sem a qual não nos teríamos salvado.

Bobbio também foi o pioneiro na análise da sociedade civil nos Cadernos do Cárcere, com um excelente texto que desencadeou diversas discussões que ajudaram na compreensão das categorias Estado/sociedade, sociedade civil/sociedade política, quando considerou a originalidade de Gramsci, evidenciando a importância do seu pensamento, sobretudo acerca da sociedade civil (BOBBIO, 1999). 
Bobbio entendeu que o marxismo tratava de teorias importantes, buscando sempre examiná-las. Afirmou a grandiosa colaboração do legado do marxismo, como filosofia política irrenunciável para o desenvolvimento da civilização.

\section{Socialismo e democracia}

Bobbio definiu-se como socialista-liberal, uma tradição muito particular na Itália. Entretanto, sua ideologia política jamais o impediu de reconhecer a importância do marxismo.

Bobbio também observa outra característica diferenciadora, a divisão entre moderados e extremistas: a posição ante a idéia de liberdade, a apreciação do método democrático. Do cruzamento destas variáveis, resultaram quatro possibilidades de doutrinas e movimentos políticos, a saber: a) na extrema-esquerda, os igualitários autoritários, descendentes do jacobinismo e do bolchevismo e adeptos do socialismo real; b) na centro-esquerda, os igualitários libertários, encontrados nos vários partidos social-democratas e social-liberais e defensores do Welfare State; c) na centro-direita, os libertários inigualitários, filiados aos partidos conservadores e liberal-conservadores e favoráveis à onda neoliberal; d) na extrema-direita, os autoritários inigualitários, originários do nazismo e do fascismo e simpatizantes das suas novas aparições (BOBBIO, 2001, p. 134-135).

Como sabemos, Bobbio é um socialista-liberal defendendo a segunda opção política - a libertária igualitária ou moderada de esquerda, onde sintetiza o seu objetivo socialista-liberal com dois elementos inseparáveis: igualdade e liberdade. Defende os princípios liberais nas questões políticas e os socialistas nas questões sociais, sendo que o ideal socialista é mais amplo do que o ideal do liberalismo, porque, ao obter mais igualdade, se estará conseguindo também mais liberdade. Para Bobbio, a democracia é uma forma de governo onde todos são livres porque são iguais.

A priori, a relação entre liberalismo e socialismo foi muito difícil. A divergência ocorre no fato da defesa ilimitada da propriedade privada. $\mathrm{O}$ socialismo descreve que a propriedade privada é a principal responsável pela desigualdade entre os homens.

Entretanto, a relação entre socialismo e democracia sempre foi possível. O processo de democratização produziria ou favorecia o advento de uma sociedade socialista, baseada na transformação da propriedade privada e 
na coletivização dos meios de produção. $\mathrm{O}$ advento da sociedade socialista reforçaria e ampliaria a participação política e, portanto, tornaria possível a plena realização da democracia, entre cujos compromissos se situam a distribuição igualitária do poder econômico e do poder político.

Esta união entre socialismo e democracia, no entender de Bobbio, é possível. Isso não quer dizer que a relação entre ambos sempre foi pacífica. Sob certos aspectos, foi polêmica. Diante de tal possibilidade, criaram-se as expressões socialismo liberal e liberalismo social.

\section{O socialismo-liberal de Norberto Bobbio}

De fato, a teoria acerca do socialismo-liberal remonta a Stuart Mill e possui importantes expoentes na Itália, como Rosselli e, mais recentemente, Norberto Bobbio. Tais pensadores, sem renunciar a uma concepção individualista da sociedade, cujo núcleo fundamental é a liberdade, afirmam a indissolubilidade da relação entre liberdade e igualdade.

A emergência e a difusão da doutrina e de movimentos socialistas e a aliança desses movimentos com os partidos democráticos reabriram o contraste histórico entre liberalismo e democracia, exatamente quando parecia ter havido uma conciliação histórica definitiva entre liberalismo e democracia.

Precisamente na reação contra o avanço do socialismo, com seu planejamento econômico e a coletivização dos meios de produção, a doutrina liberal foi cada vez mais se concentrando na defesa da economia de mercado e da livre iniciativa econômica, identificando-se como a doutrina econômica chamada liberismo, na Itália.

A Itália tem sido a precursora dos socialistas-liberais. Entre as razões para isso, destaca-se o fascismo, cuja ascensão teve o condão de aliar liberais e socialistas na luta contra o inimigo comum, a ponto até de mesclálos, como foi o caso do Partito d'Azione - o partido dos socialistas liberais, que tinha por escopo realizar a síntese entre liberalismo e socialismo.

Mesmo sem entrar em detalhes, é ilustrativo mencionar a "Revolução Liberal" de Piero Gobetti, intelectual que defendia o livre comércio, ao mesmo tempo em que admirava Lenin e colaborava com Gramsci; o "Movimento Liberal Socialista", formado em 1937 por Guido Calogero e Aldo Capitini; o "Socialismo Liberal", de Carlos Rosselli, que desejava mesclar os princípios liberais no socialismo. 
Na Itália, Rosseli esforçou-se para construir a teoria de um socialismo-liberal, mas seu primeiro grande idealizador foi um filósofo oriundo de uma corrente não marxista, onde Stuart Mill exerce um papel muito importante.

O socialismo-liberal apresenta-se como uma alternativa ao marxismo, do qual critica, filosoficamente, o determinismo e o materialismo, ou seja, a negligência das forças morais que movem a história, economicamente, o coletivismo global, politicamente, e o Estado materialista e coletivista.

Em contrapartida, o socialismo-liberal também é uma alternativa ao capitalismo liberal, que com o desenvolvimento da sociedade industrial serviu para oprimir e escravizar os trabalhadores, como também ao neoliberalismo, entendido, hoje, como uma doutrina econômica conseqüente, da qual o liberalismo político é apenas um modo de realização, nem sempre necessário; ou, em outros termos, uma defesa intransigente da liberdade econômica, da qual a liberdade política é apenas um corolário.

Para os socialistas-liberais, o socialismo originou-se do desenvolvimento histórico do liberalismo no processo de emancipação da humanidade, que objetivava, sobretudo, a liberdade. Após a emancipação política, que é obra da Revolução Francesa, seria necessária a emancipação econômica. Entretanto, a emancipação econômica não foi possível de ser realizada.

É possível se chegar ao socialismo-liberal pelo método liberal que é aberto, que só levará ao socialismo se a classe trabalhadora assim desejar. Nesse contexto, o sufrágio universal é o meio para se alcançar o poder político. É a aplicação do princípio de liberdade, é o direito de participar do poder político, mas, também, ao mesmo tempo, uma aplicação do princípio da igualdade como acesso igual aos direitos políticos.

Por fim, para Bobbio, o socialismo é um ideal a ser alcançado com a luta política permanente, mas sem identificá-lo com a coletivização dos bens de produção e muito menos com o emprego da violência para alcançar tal ideal.

\section{Considerações finais}

O desenvolvimento dos direitos humanos nas últimas décadas representou uma importante expressão na transformação do pensamento jurídico em um número crescente de países. Nesse contexto, na filosofia bobbiana, direitos humanos e democracia são elementos necessários do mesmo movimento histórico: sem direitos do homem reconhecidos e protegidos, não há democracia; sem democracia, não existem as condições mínimas para o desenvolvimento do socialismo-liberal. 
Dessa forma, os direitos humanos, a democracia e o socialismo-liberal têm sido objeto de veemente debate jurídico. Embora não se possa dizer que se trata de uma novidade, pode-se afirmar, todavia, que é um tema de visível atualidade.

Assim, como conseqüência do desenvolvimento histórico dos direitos humanos, temos a democratização da sociedade bem como a ampliação da democracia na sociedade por meio do socialismo-liberal, que, após a Segunda Guerra, tornou-se uma corrente influente na vida intelectual e política italiana.

Para Bobbio, o homem, como indivíduo, deve ser livre; como ser social, deve estar com os demais indivíduos em relação de igualdade. Liberdade e igualdade são os valores que servem como fundamento ao socialismo-liberal.

A "igualdade democrática", na "liberdade liberal", é aquela perante a lei e os direitos. Diferentemente do binômio, democracia e socialismo, onde democracia será vista como igualdade social, no binômio democracia e liberalismo, democracia terá como sinônimo a expressão sufrágio universal.

Dessa maneira, para o êxito do socialismo-liberal, o liberalismo e a democracia são, ao mesmo tempo, fins em si próprios e meios efetivos para o socialismo-liberal alcançar seu triunfo final.

Por fim, o socialismo liberal de Bobbio objetiva encontrar um terceiro caminho entre o bloco comunista e o mundo capitalista. Tal caminho teria de combinar teses marxistas e teses liberais.

\section{Referências}

BOBBIO, Norberto. Política e cultura. Torino: Giulio Einaudi, 1955. A era dos direitos. 11. ed. Rio de Janeiro: Campus, 1992. Liberalismo e democracia. 6. ed. São Paulo: Brasiliense, 1994. As ideologias e o poder em crise. 4. ed. Brasília: UNB, 1999. Direita e esquerda: razões e significados de uma distinção política. 2. ed. rev. e ampl. São Paulo: UNESP, 2001.

REGO, Walquiria Domingues Leão. Em busca do socialismo democrático. São Paulo: UNICAMP, 2001. 